\title{
Animal models of extracranial pediatric solid tumors (Review)
}

\author{
GUIDO SEITZ, SORIN ARMEANU-EBINGER, STEVEN WARMANN and JÖRG FUCHS \\ Department of Pediatric Surgery and Urology, University Children's Hospital, 72076 Tübingen, Germany
}

Received February 2, 2012; Accepted June 20, 2012

DOI: $10.3892 / \mathrm{ol} .2012 .852$

\begin{abstract}
Animal models, including xenografts, models of metastatic invasion, syngeneic models and transgenic models, are important tools for basic research in solid pediatric tumors, while humanized animal models are useful for novel immunotherapeutical approaches. Optical and molecular imaging techniques are used for in vivo imaging and may be used in conjunction with alternative treatment approaches, including photodynamic therapy. The aim of this review is to highlight the various animal models that may be used for basic research in pediatric solid tumors.
\end{abstract}

\section{Contents}

1. Introduction

2. Xenografts

3. Metastatic invasion

4. Syngeneic animal models

5. Transgenic animal models

6. Humanized animal models

7. Small animal imaging

8. Optical imaging (fluorescent proteins)

9. Photodynamic diagnosis and therapy

10. Conclusion

\section{Introduction}

Over the past 60 years, the overall survival of children suffering from cancer has increased from $10-15$ to $80 \%$ (1). Besides brain tumors, the most common types of pediatric solid tumors are neuroblastomas, nephroblastomas and rhabdomyosarcomas. Additionally, hepatoblastomas are the most common type of malignant liver tumor in children (2). Each tumor entity demonstrates diverse clinical and biological characteristics.

Correspondence to: Professor Guido Seitz, Department of Pediatric Surgery and Urology, University Children's Hospital, Hoppe-SeylerStrasse 1, 72076 Tübingen, Germany

E-mail: guido.seitz@med.uni-tuebingen.de

Key words: molecular biology, general oncology, cancer biology, solid tumors
The majority of pediatric malignancies are treated as part of cooperative treatment optimizing trials based on national and international collaborations.

Low clinical stage pediatric solid tumors demonstrate a relatively successful outcome compared to the poor outcome observed in advanced stages, in the presence of metastases or in cases of recurrent disease. Ethical considerations limit the use of in vivo studies for new therapeutic approaches. Therefore, research models are required to evaluate these approaches in a preclinical setting.

For more than 60 years, animal models have played a key role in oncological research. In recent years, the requirements for animal models have become more and more complex, focusing on tumor biology, immunology and imaging. This review documents the historical development of animal models in pediatric solid tumors and describes the latest developments in cases of neuroblastoma, nephroblastoma, rhabdomyosarcoma and hepatoblastoma.

\section{Xenografts}

In the early $1950 \mathrm{~s}$, the transplantation of a human tumor into the anterior chamber of a guinea pig eye was reported. The aim was to differentiate benign growth from malignant growth as the histopathological diagnosis was equivocal in selected cases. The main problem was that tumor growth was not often reproducible and tumor uptake was low $(3,4)$. Greene and Lund identified that the heterologous transfer of tissue depended on the developmental stage of the tumor. Ultimately, this meant that tumors containing evidence of infiltration and metastasis in the original host had a higher transplant success rate (3). Additionally, Towbin revealed that the receptivity of the host tissue was a significant factor in the success of xenotransplantation (4).

In 1958, Richards and Klausner reported the first successful transplantation of human cancer cells into untreated Swiss-Webster mice (5). In 1972, the first xenotransplantation of pediatric solid tumors was the transplantation of a rhabdomyosarcoma specimen into thymectomized hamsters, which were additionally treated with antithymocyte serum. Xenotransplantation resulted in limited local tumor growth in 2/5 animals and in the development of lung metastases in $1 / 3$ animals (6). The first successful xenotransplantation of pediatric solid tumors into mice was reported in 1975 by Helson et al. Human neuroblastoma cell lines (SK-N-SH and SK-N-MC) were subcutaneously or intraperitoneally injected into immunodeficient Swiss-Webster mice. Tumor growth 
developed at the injection site within 8 to 21 days and the tumors were histologically identical to the original tumor with evidence of morphological differentiation (7). In 1984, Rousseau-Merck et al reported a stable xenotransplantation of nephroblastoma, and revealed that a constant amount of stroma within 10 tumor passages demonstrated tumor stability (8). In 1996, Fuchs et al established the first stable and reproducible model for xenotransplantation of human hepatoblastoma into immunocompromised NMRI nu/nu mice (9). High levels of the tumor marker $\alpha$-fetoprotein (AFP) were detected in the serum of the animals. Growth rates of the tumors gradually increased during serial grafting and hematopoiesis was no longer detectable. However, a dedifferentiation could not be histologically identified.

Mice strains with extensive depletion of the innate and acquired immune system have been developed and used for xenotransplantation in order to increase the tumor uptake. This initiative is supported by the National Cancer Institute (NCI) as a means of identifying novel therapeutic agents that may have significant effects against childhood cancer (10).

There are advantages and disadvantages of subcutaneous xenograft models. The main advantages are that the results are reproducible and the models are easy to handle. The main disadvantage is that it remains unclear whether tumor behavior might be different in an orthotopic localization (e.g., liver tumors). Animal stromal cells may affect tumor-host interactions, which may impact tumor growth, development and response to therapy, and may not be studied adequately in immunodeficient animals (11-13). Additionally, the insufficient immune system of these animals may affect the behavior of the xenotransplantated tumors. Furthermore, the vascular supply is not orthotopic and studies of angiogenesis are limited. Serial propagation of the tumor cells may cause mutations resulting in xenografts with altered behavior (11). Finally, the observation time is limited to $4-8$ weeks depending on the tumor entity and speed of growth.

\section{Metastatic invasion}

Although several potential models of metastatic invasion have been formulated in the past, there remains a lack of sufficient and reproducible models. The first pediatric solid tumor model was described for murine neuroblastoma (14); however, models using human cells appear to be more appropriate for study since the biological behavior of tumors and metastases appears to be more comparable with human disease. Hata et al established a metastatic mouse model by serially transplanting human neuroblastoma cells. The study identified a high frequency of metastases to the distant organs, including the ovaries, lymph nodes and the brain, which were histologically comparable to the primary tumor (15). In 1998, a model of metastasizing human Wilms tumor in nude mice was published. Cells from a patient with anaplastic metastatic Wilms tumor were injected into the kidney parenchyma of a nude mouse. Primary renal lesions and lung metastases were observed and it was identified that the pulmonary lesions were histologically identical to the primary tumors and developed frequently (16). Daniel et al described a model of rhabdomyosarcoma lung metastases in 2001 using the TE671 cell line, which was originally established as medulloblastoma, but later reevaluated as rhab- domyosarcoma (17). Lung metastases were observed following intravenous, intramuscular and intraperitoneal injection of tumor cells into nude mice. However, a subcutaneous application of cells did not lead to the development of lung metastases in this model. Additionally, intraperitoneal injection resulted in peritoneal carcinosis, ascites and liver metastases. The metastatic process in these animals was affected by polysialic acids (PSA). Repeat injections of endoneuraminidase-N led to decreased PSA expression in primary intraperitoneal nodules and ascites; this decreased the number of liver or lung metastases. In animals with intramuscular tumors this observation could not be confirmed (17).

It appears that animal models for metastatic invasion in hepatoblastoma are difficult to establish. In 2006, Schnater et al reported the establishment of an orthotopic model of hepatoblastoma in NMRI nu/nu mice. Tumor cells were injected into the spleen and engraftment in the liver occurred following hematological spread. They also observed some loss of feature differentiation (18). Another orthotopic hepatoblastoma model with intrahepatic growth of hepatoblastoma cells was reported by Ellerkamp et al in 2011. An intrasplenic injection of hepatoblastoma cells was administered into a NOD/LtSz-scid IL $2 r \gamma^{\text {null }}$ mouse model. A splenectomy was then performed, which led to a high tumor incidence in the liver (19).

Models of metastatic invasion are advantageous since they study metastatic invasion, angiogenesis and tumor growth in host organs with human tumor biology. However, there are several associated disadvantages. Major problems include technical issues and the fact that one tumor model cannot be used for all tumor entities. Another problem is that growing tumors cannot be constantly monitored during treatment, and follow-up is often limited to the end of the experiment. However, this problem may be eluded using novel imaging techniques, including molecular or optical imaging, that allow real-time follow-up of the tumors. The interaction of the tumor with the host and the immune system remains unclear.

\section{Syngeneic animal models}

Almost 50 years ago, a syngeneic neuroblastoma animal model (C1300-NB) with spontaneously arising tumors from the spinal cord was described in strain A mice. In this model, maturation from malignant neuroblastoma to benign ganglioneuroma may be induced. TBJ-NB is a spontaneously developing clone from C1300-NB, which is able to grow rapidly and invasively with metastatic invasion (20). However, C1300-NB and other models do not genetically recapitulate human disease as no genetic alterations identified in humans are present in these models (21).

A carcinogen-induced animal model has been described for rhabdomyosarcoma. The methylcholanthrene-induced rhabdomyosarcoma MCA/76-9 syngeneic to B6 mice demonstrated histological features of an undifferentiated rhabdomyosarcoma (21).

Additionally, a model of nephroblastoma induction following transplacental administration of N-ethylnitrosurea in rats has been described. In this model, nephroblastomas, usually occurring unilaterally, were observed in $17 \%$ of all animals, and tumors revealed a wide spectrum of histological appearance with infiltrative and focal expansive growth (22). 
To date, no models of murine hepatoblastoma have been described. In 2001, Aydilik et al described an experimental liver tumor model in mice following administration of a liver carcinogen, diethylnitrosamine (DEN), in combination with phenobarbital (PB). PB promotes hepatocarcinogenesis in rodents when administered with DEN; however, these tumors are classified as hepatomas and do not resemble human hepatoblastoma (23).

An advantage of mouse models with murine tumors is that they arise spontaneously or following administration of a carcinogen. Therefore, syngeneic animal models are reproducible and easy to handle. However, the disadvantages are that those tumors are not comparable with human tumors in regards to tumor biology, and genetic alterations of the tumors are not reproducible. Finally, the etiological theory of embryonal tumors originating from pluripotent stem cells is contradictory to the development of syngeneic murine tumors arising from mutations.

\section{Transgenic animal models}

In order to study the effects of genetic alterations, knock-out mouse models have been established in pediatric solid tumors. Mice with mutations of the tumor suppressor gene p53 (p53 $3^{-/-}$mouse) are susceptible to developing murine sarcoma. Approximately $1 / 3$ of all detected tumors in this model are different sarcomas, including undifferentiated sarcomas, angiosarcomas or osteosarcomas $(11,24)$. Newer models focus on renegade transcription factors. In alveolar rhabdomyosarcoma, a $\mathrm{t}(2 ; 13)$ or occasionally $\mathrm{t}(1 ; 13)$ translocation may be identified, which fuses the paired-box transcription factor Pax3 (occasionally Pax7) with the transactivation domain of the forkhead transcription factor Fkhr $(11,25)$. The Pax3-Fkhr fusion gene may have oncogenic functions, which could lead to uncontrolled cell growth (11). Pax3-Fkhr-positive alveolar rhabdomyosarcoma is more aggressive than Pax7-Fkhr-positive or fusion-negative alveolar rhabdomyosarcoma (26). Initially, a Pax3-Fkhr knock-in mouse model was created, which did not lead to the development of alveolar rhabdomyosarcoma tumors (27). Therefore, a conditional knock-in allele of Pax3-Fkhr in the Pax3 locus was generated. A mouse model of alveolar rhabdomyosarcoma was established by simultaneously activating Pax3-Fkhr expression and inactivating p53 or Cdkn2 $\alpha$ (28). This is the closest model to human alveolar rhabdomyosarcoma at the whole-genome level (26).

In neuroblastoma, the single most predictive marker for adverse outcome is the amplification of the v-myc myelocytomatosis viral related oncogene, neuroblastoma derived (avian), or MYCN (21). Transgenic mice overexpressing MYCN in neuroectodermal cells develop neuroblastoma. Studies have described thoracic paraspinal and abdominal tumors and demonstrated a MYCN dose-dependent tumor incidence of up to $100 \%$ (29). Genomic hybridization has been used to identify the gains and losses at seven chromosomal regions, which are comparable to abnormalities detected in human neuroblastoma (29).

To the best of our knowledge, transgenic animal models for hepatoblastoma and nephroblastoma have not been described.

The advantages of transgenic tumor models are that they resemble the biological and genetic aspects of the tumor, and tumor development in mice appears to be comparable to human tumors. A major disadvantage of these models is that they are murine tumors and studies of human tumor biology appear to be limited. Another disadvantage is that transgenic animal models are limited to few tumor entities with specific genetic alterations (i.e. alveolar rhabdomyosarcoma). Additionally, adoptive immune therapy in humanized settings is not feasible, since applied differentiated immune cells would only be useful for a short period of time without regulatory effects.

\section{Humanized animal models}

Sufficient and reproducible animal models are necessary for the investigation of novel immunotherapeutic approaches. Mouse models are regarded as sufficient tools for immunological studies, but are incapable of accurately predicting the outcome in humans (30). Therefore, over the past 20 years, mouse models with humanized immune systems have been established (31). To date, the two most commonly used models are the BALB/c-Rag $2^{\text {null }}$ IL $2 \mathrm{r} \gamma^{\text {null }}$ (32) and the NOD/LtSz-scid IL2 $r \gamma^{\text {null }}$ mouse models (33). These models are based on the understanding that the xenotransplantation of human hematopoietic stem cells (HSCs) leads to an engraftment of transplanted cells, which results in a consecutive production of human myeloid and lymphoid cell lineages (33). In the BALB/c-Rag2 ${ }^{\text {null }}$ IL2 $r \gamma^{\text {null }}$ mouse model, CD $34^{+}$human cord blood cells are injected into the liver of newborn animals, which leads to the de novo development of B-, T- and dendritic cells (32). In the NOD/LtSz-scid IL $2 \mathrm{r} \gamma^{\text {null }}$ mouse model, animals are irradiated with $300 \mathrm{cGy}$ and $\mathrm{CD} 34^{+}$cell fractions of mobilized HSCs are then injected in the tail vein. This leads to engraftment with HSCs, generating human $\mathrm{CD} 45^{+}$cells in the host bone marrow, including HSCs, B-, NK, myeloid and plasmacytoid dendritic cells (33). Newborn animals are more advantageous than adult animals as an exogenous supply of human IL-7 for thymopoiesis is not required and they have an improved bone marrow chimerism $(33,34)$. However, co-administration of the human Fc-IL7 fusion protein results in high percentages of human $\mathrm{CD} 4^{+} \mathrm{CD} 8^{+}$thymocytes as well as human $\mathrm{CD}^{+}{ }^{+} \mathrm{CD} 8{ }^{-}$and $\mathrm{CD}^{-} \mathrm{CD}^{+}$peripheral blood and splenic T-cells in adult animals (33).

Humanized animal models are useful for hematopoietic reconstitution, microbial infection and vaccine development investigations $(33,34)$. To date, only one humanized mouse model combined with a solid pediatric tumor has been published, which was described by our group in 2010 (34). In this model, NOD/LtSz-scid IL2 $r \gamma^{\text {null }}$ mice underwent sublethal irradiation with cesium 137 followed by stem cell transplantation with human $\mathrm{CD} 34^{+}$cells. Following successful stem cell engraftment, animals underwent xenotransplantation of human alveolar or embryonal rhabdomyosarcoma cells. A successful engraftment was identified in $85 \%$ of animals with human myeloid and lymphoid lineages, of which the majority of cells were B- and T-cells. Due to the more aggressive nature of the alveolar rhabdomyosarcoma, xenografts were more successfully established compared to those of the embryonal rhabdomyosarcoma. The cell viability was lower in animals undergoing $\mathrm{CD} 34^{+}$transplantation compared to controls without $\mathrm{CD}_{3} 4^{+}$transplantation, which may be due to 
the inhibitory effects of human immune cells (34). This model may also be used in other pediatric solid tumors for the evaluation of immunotherapy.

Humanized animal models are useful for the study of interactions between tumors and the human immune system. Conditions in these models closely resemble human conditions, but unknown factors influencing the original immune system of the animals remain. A major disadvantage is that these models are highly complex and difficult to handle. Animals require extensive care following stem cell transplantation and there is a delay until the start of the experiments. This makes the experiments time-consuming and large series of animals are difficult to analyze.

\section{Small animal imaging}

With the emerging use of orthotopic and metastatic tumor models, tools became necessary for monitoring clinically unamenable tumors with regard to uptake, development or behavior under treatment.

In the clinical setting, certain tumors are monitored via serum tumor markers. This helps to predict the effects of treatment and provides early information with regard to possible tumor relapses in conditions where there is a lack of sensitivity of imaging methods due to small tumor sizes. In pediatric oncology, this is the case for hepatoblastoma and certain types of germ cell tumors, which secrete AFP or $\beta$-HCG. Hepatoblastoma xenografts also secrete human AFP, which is measurable in the serum of transplanted animals (9).

Microcomputed tomography (micro-CT) is mainly used to provide phenotypic descriptions of genomic models. It provides a platform for cancer assessment at high resolution, and is proven to be powerful, particularly in tracking pulmonary lesions. The addition of longitudinal assessment studies has helped to overcome the limitation of single time-point imaging (35).

Positron emission tomography (PET) is used to differentiate tumor nodules from surrounding healthy tissue. This method is based on the differential uptake of specific tracers in tissue areas of varying activity. Several tracers are currently used in small animals, which provide information on onset, progression and behavior under the treatment of solid tumors. The method of PET/CT imaging combines the functional PET analysis with morphological CT assessment providing a sensitive resolution from $3 \mathrm{~mm}$ onwards $(36,37)$.

Single photon emission computed tomography (SPECT) has been reported to be a valuable tool for monitoring orthotopic tumor models through combining bioluminescence with high-resolution CT analyses (38). Thus, investigators are able to differentiate small tumor nodules from surrounding tissue in a single investigation.

Magnetic resonance imaging (MRI) has been increasingly adapted for small animals and currently represents the most frequently used imaging tool for in vivo solid tumor models. To date, several MRI techniques are applied, including conventional, diffusion-weighted or high-field MRI. Longitudinal in vivo studies are possible with these techniques, providing data on tumor uptake, progression and response to therapy. In recent years, MRI has been frequently used for monitoring photodynamic therapy (PDT) in mice (39-41).

\section{Optical imaging (fluorescent proteins)}

Fluorescent proteins have been mainly used in various adult tumors (42). The first description of xenotransplanted human rhabdomyosarcoma following transfection with red fluorescent protein was described by our group in 2006 (43). Superficial lesions are easy to detect, but metastases in deeper regions of the body, including the thoracic cavity, are more difficult. Therefore, additional measures, including skin flap techniques, are required to visualize these lesions. The use of newer fluorescent proteins (e.g., far-red fluorescent proteins), which have a longer excitation and emission wavelength, has led to more efficient tissue penetration (44). Following the establishment of whole tumor visualization, the subsequent target was to visualize and observe tumor cells at single cell level. In 2008, we described the imaging of cell trafficking and metastatic invasion in childhood rhabdomyosarcoma. Cancer cells were tracked along larger vessels and were often observed to arrest at the vessel junctions, particularly those with a smaller diameter. It was also observed that the tumor cells in larger vessels appeared to be more spherical, while tumor cells in smaller vessels were stretched. An accumulation of cancer cells was identified at vessel junctions. In larger vessels, tumor cells attached to the vessel walls and an extravasation was observed $12 \mathrm{~h}$ later. The study concluded that the experimental metastatic invasion of rhabdomyosarcoma cells was caused by tumor cell accumulation and extravasation (45).

An advantage of optical imaging is that it is transferable to other tumors and may be useful for therapeutic studies. Modern imaging techniques using fluorescent proteins allow an optimized visualization of tumors and metastases in vivo. It is possible to monitor the size of the lesion in the animal during treatment in a non-invasive manner. Additionally, mechanisms of metastatic invasion may be followed in real time. The major disadvantages of optical imaging are autofluorescence, low detectability of small lesions with a low number of tumor cells and the requirement of additional imaging techniques for deep lesions.

\section{Photodynamic diagnosis and therapy}

Several techniques using photodynamic agents have been described for pediatric solid tumors. Till et al initially described photodynamic videoscopic fluorescent diagnosis of peritoneal and thoracic metastases of human hepatoblastoma in nude rats using 5-aminolevulinic acid (5-ALA) (46).

Besides photodynamic fluorescence diagnosis, there are also models for PDT in several types of cancer. Activation of a photodynamic drug using the appropriate light wavelength leads to the development of singlet oxygen radicals inducing cytotoxic effects on cancer cells (47). To date, only one animal model for PDT in pediatric solid tumors has been described. Bergmann et al investigated the effectiveness of 5-ALA-induced PDT in human hepatoblastoma. Following in vitro studies, PDT in nude rat models was conducted. Irradiation with green light revealed a higher fluorescence signal in implanted tumors compared to normal liver tissues. A histological study of all irradiated tumors identified phototoxic necrosis as evidence of successful PDT (48).

In conclusion, photodynamic agents may be used for in vivo detection of tumors. These substances appear to have certain 
Table I. Animal models in pediatric solid tumors.

\begin{tabular}{|c|c|c|c|}
\hline Animal model & Advantages & Disadvantages & Application \\
\hline Xenografts & $\begin{array}{l}\text { Easy to handle } \\
\text { Reproducible } \\
\text { Tumor volume measurable } \\
\text { Human tumor biology }\end{array}$ & $\begin{array}{l}\text { Not orthotopic } \\
\text { Tumor-host-interaction } \\
\text { Murine immune system } \\
\text { Vascular supply } \\
\text { Limited observation time } \\
\text { Mutations }\end{array}$ & $\begin{array}{l}\text { Drug testing } \\
\text { Biological studies } \\
\text { Serial grafting }\end{array}$ \\
\hline $\begin{array}{l}\text { Metastatic } \\
\text { invasion }\end{array}$ & $\begin{array}{l}\text { Tumor growth in host organs } \\
\text { Human tumor biology } \\
\text { Metastatic invasion } \\
\text { Angiogenesis }\end{array}$ & $\begin{array}{l}\text { Technical challenges } \\
\text { Not for all tumor entities } \\
\text { Detection } \\
\text { Follow-up/monitoring } \\
\text { Reproducibility } \\
\text { Tumor-host-interaction }\end{array}$ & $\begin{array}{l}\text { Drug testing } \\
\text { Metastatic invasion }\end{array}$ \\
\hline Syngeneic & $\begin{array}{l}\text { Orthotopic model } \\
\text { Metastatic invasion } \\
\text { Histology } \\
\text { Easy to handle } \\
\text { Reproducibility }\end{array}$ & $\begin{array}{l}\text { Genetic differences to human } \\
\text { Undifferentiated tumors } \\
\text { Few entities } \\
\text { Murine tumors }\end{array}$ & $\begin{array}{l}\text { Vaccination } \\
\text { Suicide gene therapy } \\
\text { Tumor biology }\end{array}$ \\
\hline Transgenic & $\begin{array}{l}\text { Genetic background } \\
\text { Histology } \\
\text { Tumor development comparable } \\
\text { to humans }\end{array}$ & $\begin{array}{l}\text { Difficult to establish } \\
\text { Not all entities } \\
\text { Different sites of tumors } \\
\text { Long latency in tumor formation } \\
\text { Murine tumors }\end{array}$ & $\begin{array}{l}\text { Tumorigenesis } \\
\text { Gene therapy }\end{array}$ \\
\hline Humanized & $\begin{array}{l}\text { Tumor-host-interaction } \\
\text { Human conditions } \\
\text { Xenografts possible }\end{array}$ & $\begin{array}{l}\text { Complex models } \\
\text { Difficult to handle } \\
\text { Time consuming } \\
\text { Small series } \\
\text { Success rate of the immune } \\
\text { system }\end{array}$ & $\begin{array}{l}\text { Immunotherapy } \\
\text { Metastatic invasion } \\
\text { Drug testing }\end{array}$ \\
\hline $\begin{array}{l}\text { Small animal } \\
\text { imaging }\end{array}$ & $\begin{array}{l}\text { Evaluation of drug safety } \\
\text { in immature settings }\end{array}$ & $\begin{array}{l}\text { Not necessary in all cases } \\
\text { Comparability to humans }\end{array}$ & Drug testing \\
\hline Optical imaging & $\begin{array}{l}\text { In vivo visualization of tumors and } \\
\text { metastases following transfection } \\
\text { Non invasive follow-up } \\
\text { Cancer cell trafficking }\end{array}$ & $\begin{array}{l}\text { Autofluorescence } \\
\text { Weak signals } \\
\text { Problems with deep lesions }\end{array}$ & $\begin{array}{l}\text { Metastatic invasion } \\
\text { Drug testing } \\
\text { Biological studies } \\
\text { In vivo imaging }\end{array}$ \\
\hline $\begin{array}{l}\text { Photodynamic } \\
\text { diagnosis } \\
\text { and therapy }\end{array}$ & $\begin{array}{l}\text { In vivo visualization of tumors and } \\
\text { metastases without transfection } \\
\text { Visualization of resection margins } \\
\text { Photodynamic therapy }\end{array}$ & $\begin{array}{l}\text { No specific uptake in tumors } \\
\text { Photodermatitis }\end{array}$ & $\begin{array}{l}\text { In vivo imaging } \\
\text { Fluorescence laparoscopy } \\
\text { Photodynamic therapy }\end{array}$ \\
\hline
\end{tabular}

advantages to their use in humans. They are not required to be included into the genome of a cancer cell, discrimination between tumors and the surrounding tissue (e.g., resection margins) is feasible and PDT may be conducted. The disadvantages of photodynamic agents are the major side effects (e.g., severe photodermatitis) and the requirement for specific uptake in cancer cells.

\section{Conclusion}

Several animal models exist for solid pediatric tumors, including hepatoblastoma, nephroblastoma, rhabdomyosarcoma and neuroblastoma (Table I). Models with murine tumors are not as favorable as they do not completely resemble human disease. The decision on which specific animal model to use should depend on the specific situation. The future perspective for animal models in pediatric solid tumors appears to be double-tracked. Besides xenograft models, which remain extremely useful in evaluating new drugs, therapies and mechanisms, there is likely to be further research on highly complex immuno-adapted animal models. These models may aid in the understanding of the interactions between tumors and the human immune system, and in the evaluation of novel immunotherapeutic treatment approaches. Investigations are likely to be limited to specific situations as these animal models are difficult to handle and extremely expensive. Therefore, they appear to be inappropriate for broad screenings. 


\section{References}

1. Yanagisawa T, Bartels U and Bouffet E: Role of prognostic factors in the management of pediatric solid tumors. Ann NY Acad Sci 1138: 32-42, 2008.

2. Davidoff AM: Pediatric oncology. Semin Pediatr Surg 19: 225-233, 2010.

3. Greene HSN and Lund PK: The heterologous transplantation of human cancers. Cancer Res 4: 352-363, 1944.

4. Towbin A: The heterologous transplantation of human tumors. Cancer Res 11: 716-722, 1951.

5. Richards V and Klausner C: The heterologous transplantation of human cancer in untreated Swiss-Webster mice. Surgery 44: 181-198, 1958.

6. Cobb LM: Metastatic spread of human tumour implanted into thymectomized, antithymocyte serum treated hamsters. Br J Cancer 26: 183-189, 1972.

7. Helson L, Das SK and Hajdu SI: Human neuroblastoma in nude mice. Cancer Res 35: 2594-2599, 1975.

8. Rousseau-Merck MF, Cottreau D and Kahn A: Isoenzyme pattern in serially xenotransplanted childhood tumors. Cancer Res 44: 1163-1166, 1984

9. Fuchs J, Schmidt D, Pietsch T, Miller K and von Schweinitz D Successful transplantation of human hepatoblastoma into immunodeficient mice. J Pediatr Surg 31: 1241-1246, 1996.

10. Houghton PJ: The pediatric preclinical testing program: description of models and early testing results. Pediatr Blood Canc 49: 928-940, 2007.

11. Dodd RD, Mito JK and Kirsch DG: Animal models of soft-tissue sarcoma. Dis Mech Mod 3: 557-566, 2010.

12. List K, Szabo R, Molinolo A, et al: Deregulated matripase causes ras-independent multistage carcinogenesis and promotes ras-mediated malignant transformation. Genes Dev 19 1934-1950, 2005.

13. Meads MB, Gatenby RA and Dalton WS: Environment-mediated drug resistance: a major contributor to minimal residual disease. Nat Rev Cancer 9: 665-674, 2009.

14. Finklestein JZ, Tittle K, Meshnik R and Weiner J: Murine neuroblastoma: further evaluation of the $\mathrm{C} 1300$ model with single antitumor agents. Cancer Chemother Rep 59: 975-983, 1975.

15. Hata JI, Ueyama Y, Tamaoki N, Furukawa T and Morita K: Human neuroblastoma serially transplanted in nude mice and metastases. Cancer 42: 468-473, 1978 .

16. Marvin MR, Kayton ML, O'Toole KM, et al: A metastasizing model of anaplastic human Wilms tumor in the nude mouse. Eur J Pediatr Surg 8: 295-298, 1998.

17. Daniel L, Durbec P, Gautherot E, Rouvier E, Rougon G and Figarella-Branger D: A nude mice model of human rhabdomyosarcoma lung metastases for evaluating the role of polysialic acids in the metastatic process. Oncogene 20: 997-1004, 2001.

18. Schnater JM, Bruder E, Bertschin S, et al: Subcutaneous and intrahepatic growth of human hepatoblastoma in immunodeficient mice. J Hepatol 45: 377-386, 2006.

19. Ellerkamp V, Armeanu-Ebinger S, Wenz J, Warmann SW, Schäfer J, Ruck P and Fuchs J: Successful establishment of an orthotopic hepatoblastoma xenograft in NOD/LtSz-scid IL2R $\gamma^{\text {null }}$-mice NULL mice. PLoS One 6: e23419, 2011.

20. Ziegler MM, Ishizu H, Nagabuchi E, Takada N and Arya G: A comparative review of the immunobiology of murine neuroblastoma and human neuroblastoma. Cancer 79: 1757-1766, 1997.

21. Beltinger C and Debatin KM: Murine models for experimental therapy of pediatric solid tumors with poor prognosis. Int J Cancer 92: 313-318, 2001

22. Hard GC: Differential renal tumor response to N-ethylnitrosourea and dimethylnitrosamine in the $\mathrm{Nb}$ rat: basis for a new rodent model of nephroblastoma. Carcinogenesis 6: 1551-1558, 1985.

23. Aydinlik H, Nguyen TD, Moennikes O, Buchmann A and Schwarz M: Selective pressure during tumor promotion by Phenobarbital leads to clonal outgrowth of $\beta$-catenin-mutated mouse liver tumors. Oncogene 20: 7812-7816, 2001.

24. Donehower LA, Harvey M, Slagle BL, McArthur MJ, Montgomery CA Jr, Butel JS and Bradley A: Mice deficient for p53 are developmentally normal but susceptible for spontaneous tumors. Nature 356: 215-221, 1992.

25. Barr FG: Gene fusions involving PAX and FOX family members in alveolar rhabdomyosarcoma. Oncogene 20: 5736-5746, 2001.
26. Nishijo K, Chen QR, Zhang L, et al: Credentialing a preclinical mouse model of alveolar rhabdomyosarcoma. Cancer Res 69: 2902-2911, 2009

27. Lagutina I, Conway SJ, Sublett J and Grosveld GC: Pax3-FKHR knock-in mice show developmental aberrations but do not develop tumors. Mol Cell Biol 22: 7204-7216, 2002.

28. Keller C and Capecchi MR: New genetic tactics to model alveolar rhabdomyosarcoma in the mouse. Cancer Res 65: 7530-7532, 2005.

29. Weiss WA, Aldape K, Mohapatra G, Feuerstein BG and Bishop JM: Targeted expression of MYCN causes neuroblastoma in transgenic mice. EMBO J 16: 2985-2995, 1997.

30. Macchiarini F, Manz MG, Palucka AK and Shultz LD: Humanized mice: are we there yet? J Exp Med 202: 1307-1311, 2005

31. Manz MG and Di Santo JP: Renaissance for mouse models of human hematopoiesis and immunobiology. Nat Immunol 10: 1039-1042, 2009.

32. Traggiai E, Chicha L, Mazzucchelli L, Bronz L, Piffaretti JC, Lanzavecchia A and Manz MG: Development of a human adaptive immune adaptive immune system in a cord blood cell-transplanted mice. Science 304: 104-107, 2004.

33. Shultz LD, Lyons BL, Burzenski LM, et al: Human lymphoid and myeloid cell development in NOD/LtSz-scid IL2R gamma null mice engrafted with mobilized human hemopoietic stem cells. J Immunol 174: 6477-6489, 2005.

34. Seitz G, Pfeiffer M, Fuchs J, et al: Establishment of a rhabdomyosarcoma xenograft model in human-adapted mice. Oncol Rep 24: 1067-1072, 2010.

35. Namati E, Thiesse J, Sieren JC, Ross A, Hoffmann EA and McLennan G: Longitudinal assessment of lung cancer progression in the mouse using in vivo micro-CT imaging. Med Phys 37: 4793-4805, 2010.

36. Nielsen $\mathrm{CH}$, Kimura RH, Withofs N, et al: PET imaging of tumor neovascularisation in a transgenic mouse model with a novel 64Cu-DOTA-knottin peptide. Cancer Res 70: 9022-9030, 2010.

37. Walter MA, Hildebrandt IJ, Hacke K, et al: Small-animal PET/CT for monitoring the development and response to chemotherapy of thymic lymphoma in Trp53 $3^{-/}$mice. J Nucl Med 51: $1285-1292,2010$

38. Buckle T and van Leeuwen FW: Validation of intratracheal installation of lung tumor cells in mice using single photon emission computed tomography/computed tomography imaging. Lab Anim 44: 40-45, 2010.

39. Wang $\mathrm{H}$ and Fei B: Diffusion-weighted MRI for monitoring tumor response to photodynamic therapy in an animal model. J Magn Reson Imaging 32: 409-417, 2010

40. Fei B, Wang H, Meyers JD, Feyes DK, Oleinick NL and Duerk JL: High-field magnetic resonance imaging of the response of human prostate cancer to Pc 4-based photodynamic therapy in an animal model. Lasers Surg Med 39: 723-730, 2007.

41. Plaks V, Koudinova N, Nevo U, et al: Photodynamic therapy of established prostatic adenocarcinoma with TOOKAD: a biphasic apparent diffusion coefficient change as potential early MRI response marker. Neoplasia 6: 224-233, 2004.

42. Hoffman RM: Green fluorescent protein imaging of tumor growth, metastasis, and angiogenesis in mouse models. Lancet Oncol 3: 546-556, 2002

43. Seitz G, Warmann SW, Fuchs J, et al: Visualization of xenotransplanted human rhabdomyosarcoma after transfection with red fluorescent protein. J Pediatr Surg 41: 1369-1376, 2006.

44. Baird GS, Zacharias DA and Tsien RY: Biochemisty, mutagenesis, and oligomerization of DsRed, a red fluorescent protein from coral. Proc Natl Acad Sci USA 97: 11984-11989, 2000.

45. Seitz G, Warmann SW, Fuchs J, et al: Imaging of cell trafficking and metastases of paediatric rhabdomyosarcoma. Cell Prolif 41: 365-374, 2008.

46. Till H, Bergmann F, Metzger R, Haeberle B, Schaeffer K, von Schweinitz D and Prosst RL: Videoscopic fluorescence diagnosis of peritoneal and thoracic metastases from human hepatoblastoma in nude rats. Surg Endosc 19: 1483-1486, 2005.

47. Hendrickx N, Volanti C, Moens U, et al: Up-regulation of cyclooxygenase- 2 and apoptosis resistance by $\mathrm{p} 38$ MAOK in hypericin-mediated photodynamic therapy of human cancer cells. J Biol Chem 278: 52231-52239, 2003.

48. Bergmann F, Stepp H, Metzger R, Rolle U, Johannson A and Till H: In vitro and in vivo evaluation of photodynamic techniques for the experimental treatment of human hepatoblastoma and neuroblastoma: preliminary results. Pediatr Surg Int 24: 1331-1333, 2008. 